Albers, G., Francke, A.L., Veer, A.J.E. de, Bilsen, J., Onwuteaka-Philipsen, B.D. Attitudes of nursing staff towards involvement in medical end-of-life decisions: a national survey study.

\begin{tabular}{|l|l|}
\hline Postprint Version & 1.0 \\
\hline Journal website & http://www.sciencedirect.com/science/article/pii/S0738399113003935 \\
\hline Pubmed link & http://www.ncbi.nlm.nih.gov/pubmed/24268920 \\
\hline DOI & 10.1016/j.pec.2013.09.018
\end{tabular}

This is a NIVEL certified Post Print, more info at http://www.nivel.eu

\title{
Attitudes of nursing staff towards involvement in medical end-of-life decisions: a national survey study
}

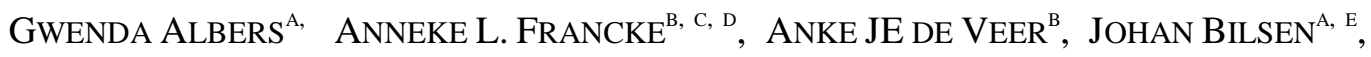 \\ BREGJE D. ONWUTEAKA-PHILIPSEN ${ }^{\mathrm{C}, \text { D }}$ \\ ${ }^{a}$ End-of-Life Care Research Group, Ghent University \& Vrije Universiteit Brussel, Brussels, \\ Belgium \\ ${ }^{b}$ NIVEL, Netherlands Institute of Health Services Research, Utrecht \\ ${ }^{c}$ Department of Public and Occupational Health, EMGO Institute for Health and Care \\ Research, VU University Medical Center Amsterdam \\ d Expertise Center for Palliative Care Amsterdam, VU University Medical Center, \\ Amsterdam, Netherlands \\ ${ }^{\mathrm{e}}$ Department of Public Health, Vrije Universiteit Brussel, Brussels, Belgium
}

\begin{abstract}
Objectives To investigate nursing staff attitudes towards involvement and role in end-of-life decisions (ELD) and the relationships with sociodemographic and work-related characteristics.

Methods Survey study among nationally representative Dutch research sample consisting of care professionals. Nursing Staff working in hospitals, home care, nursing homes or homes for the elderly were sent ELD-questionnaire.

Results Response: 66\% ( $n=587)$. Most respondents had been involved in ELD. Three quarters wanted to be involved in whole ELD process; $58 \%$ agreed that decisions to withhold/withdraw treatment ought to be discussed with the nurses involved; $64 \%$ believed patients would talk rather to nurses than physicians; $72 \%$ thought physicians are usually prepared to listen to nurses' opinions. Hospital and highly educated nursing staff indicated relatively more often that they want to be involved in ELD.

Conclusion Majority of nursing staff want to be involved in ELD. Work setting and educational level are determining factors in attitudes of nursing staff regarding involvement in ELD.

Practice Implications: Awareness on the important role nurses have and want to have in ELD should be raised, and taken into account in trainings on end-of-life care for nurses and physicians and development of guidelines for communication about ELD between patients, nursing staff and physicians.
\end{abstract}


Albers, G., Francke, A.L., Veer, A.J.E. de, Bilsen, J., Onwuteaka-Philipsen, B.D. Attitudes of nursing staff towards involvement in medical end-of-life decisions: a national survey study. Patient Education and Counseling: 2014, 94(1), 4-9

\section{INTRODUCTION}

Populations in developed nations are ageing rapidly. Numbers of deaths are expected to rise each year in the coming decades, most of them due to chronic diseases such as cancer, heart disease, chronic respiratory diseases and dementia [1]. The progression of chronic diseases generally entails a period of impaired health and a protracted process of care and ultimately dying.

Suffering from severe chronic illness and disability may require a period of complex decision making by patients, family, caregivers and the clinical team in the last stage of the patient's life. Medical end of life decision-making often involve weighing up the burden of implementing, withholding, continuing or withdrawing treatments, and the benefits such as improvement of the quality of life of patient and family by prevention and relief of suffering. A number of studies found that dying and death are frequently preceded by medical end-of-life decisions in different European countries [2], [3] and [4]. In a robust comparative study in six European countries, the proportion of all deaths preceded by any medical end-of-life decision (ELD) ranged from 23\% in Italy to 51\% in Switzerland, while in the Netherlands this percentage was $44 \%$ [4].

Decision-making at the end of life might be related to medical treatments with a definite life-shortening effect (e.g. euthanasia and physician-assisted suicide).

However, this paper focuses on ELD with a possible life-shortening effect, including withholding or withdrawing a potentially life-prolonging treatment such as artificial hydration and nutrition, intensifying drug treatment to alleviate symptoms but with possible life-shortening side effects, and palliative sedation. These decisions can take place in any setting where patients die, e.g. hospitals, hospices, nursing homes, and at home.

Although physicians are formally responsible for ELD, nurses are likely to be involved in the decision-making process. Nurses often have closer and more frequent contact with patients than physicians. The contact between nursing staff and patients who are severely ill or dying is often informal and personal, and patients are therefore likely to speak to nurses about their hopes, wishes and concerns. Consequently, nurses can be an important source of information for a physician who has to decide about forgoing or starting a medical treatment. Two studies performed in the Netherlands showed that nurses were involved in end-of-life decision-making by the physician in more than half of all cases [5] and [6]. The study by Van Bruchem-van de Scheur et al. indicated that there were consultations between physicians and nursing staff in 56\% of the decisions about intensifying drug treatment to alleviate pain or other symptoms [6]. In the study by De Veer et al., it was found that $84 \%$ of Dutch nurses had been involved in decisions about stopping parenteral hydration and nutrition during the previous two years and $91 \%$ had been involved in decisions about intensifying drug treatment to alleviate symptoms [5].

The studies mentioned above suggest that consultation between nurses and physicians about medical ELD is quite common. However, whether physicians consult a nurse or not in case of ELD may be related to nurses' own attitudes regarding their roles and desired involvement in ELD. Inghelbrecht and colleagues investigated the attitudes of nurses in Flanders (the Dutch-speaking part of Belgium) to ELD. Most nurses in Flanders indicated that they have an important role to play in 
Albers, G., Francke, A.L., Veer, A.J.E. de, Bilsen, J., Onwuteaka-Philipsen, B.D. Attitudes of nursing staff towards involvement in medical end-of-life decisions: a national survey study. Patient Education and Counseling: 2014, 94(1), 4-9

ELD. However, nurses' work settings appeared to be related to their attitudes to their role in end-of-life decision-making [7]. To gain more insight into the attitudes of Dutch nursing staff in particular to involvement and roles in ELD as well as of the relationships between those attitudes on the one hand and sociodemographic and work-related characteristics on the other hand, we carried out the survey study described in this paper.

\section{METHODS}

\subsection{Sample}

The study sample was recruited from a pre-existing nationally representative research sample of nursing staff in the Netherlands, hereinafter referred to as the Nursing Staff Panel [5], [8], [9] and [10]. This Panel consists of a permanent group of Certified Nursing Assistants (CNAs) and Registered Nurses (RNs) who are prepared to fill in questionnaires (at least twice a year) on current topics in nursing care. Compared to CNAs in most other countries, Dutch CNAs go through a rather lengthy vocational nursing training program lasting three years. Dutch RNs are educated at two different levels and comprise nursing staff at associate degree level

(3-3.5 years of basic nursing education) and nursing staff at a bachelor's level (at least 4 years of basic nursing education). The Nursing Staff Panel is representative of nursing staff in the main healthcare settings in the Netherlands, i.e. hospitals, home care, nursing homes and homes for the elderly, psychiatry, and care for the mentally disabled. However, data from nursing staff working in psychiatry or in organizations for the mentally disabled were not included in the analysis for this paper, as end-oflife care is less common in these settings than in the other healthcare settings mentioned.

\subsection{Data collection and survey questionnaire}

In 2011, all 903 participants of the Nursing Staff panel who worked in hospitals, home care, nursing homes and homes for the elderly were sent our survey questionnaire. A total of 587 completed the questionnaire. The questionnaire contained questions on actual experiences and attitudes regarding involvement and roles in ELD. These statements were derived from an existing survey questionnaire developed, tested and used in research in Flanders [7]. The participants were asked to what extent they agreed with each statement (strongly disagree $=-2$, disagree $=-1$, neutral $=0$, agree $=1$, strongly agree $=2$ ). The nine statements fall into three main topics: the perceived position of the nurse with respect to the patient when an ELD is being considered (two statements), the perceived position of the nurse with respect to the physician when an ELD is being considered (two statements), and the perceived role of nursing staff in ELD (5 statements). The statements are listed in Table 2. We also asked some questions on background characteristics and work-related characteristics.

\subsection{Analysis}

Descriptive statistics were used to describe the sociodemographic and work-related characteristics of the Nursing Staff Panel as a whole and broken down by work 
Albers, G., Francke, A.L., Veer, A.J.E. de, Bilsen, J., Onwuteaka-Philipsen, B.D. Attitudes of nursing staff towards involvement in medical end-of-life decisions: a national survey study. Patient Education and Counseling: 2014, 94(1), 4-9

setting. The five response categories for the statements were condensed into three: 1) agree or strongly agree, 2) neutral and 3) disagree or strongly disagree. Percentages were then presented. In order to explore if there were any sociodemographic and work-related characteristics associated with the agreement of nursing staff on the statements a backward multiple logistic regression (removal at $\mathrm{p}<0.05$ ) was performed and odds ratios and 95\% confidence intervals were calculated. We split the response categories of the dependent variables into two, agreement (agree and strongly agree) versus the other categories (neutral, disagree and strongly disagree). The following factors were entered in the analysis: age, gender, level of education, having a belief or religion important in one's life, work setting, had been involved in some kind of ELD in the previous two years, and having had basic education or continuing education about ELD. The independent variables have been dichotomized for this analysis. Then separate logistic regression models were fitted for each statement. All analyses were performed using SPSS 16.0.

\section{RESULTS}

\subsection{Response and characteristics of nursing staff}

The overall response rate was $66 \%$, ranging from $59 \%$ in nursing homes to $74 \%$ in academic hospitals. Table 1 shows the characteristics of the study participants. The majority were female and aged over 40. Fifty-three per cent of respondents were CNAs, of whom most were working in homes for the elderly and nursing homes. Hospital nursing staff consisted mainly of RNs (99\%). Fourteen per cent were working in a team or at a department specialized in palliative care. Eighty-four per cent had cared for a terminally ill patient over the last two years and $83 \%$ had been involved in some kind of ELD during the last two years. Respondents working in nursing homes and homes for the elderly were most often involved in end-of-life care and ELD. More than half of the nursing staff received basic education or continuing education about ELD, except for those working in homes for the elderly (43\%).

\section{[TABLE 1. ]}

\subsection{Attitudes of nursing staff}

Table 2 shows that $64 \%$ agreed that patients would rather talk to a nurse about ELD than to a physician, and 38\% agreed that nurses are in a better position to assess patients' end-of-life wishes than a physician. A quarter of all nurses find themselves in a subordinate position that makes communication with the physician difficult, and $72 \%$ thought that physicians are usually prepared to listen to nurses' opinions about terminally ill patients. Approximately three-quarters of the respondents believed that decisions with a life-shortening effect were part of their job (71\%), and agreed that they should be involved in the whole process of ELD (74\%). Fifty-eight per cent agreed that decisions to withhold or withdraw life-sustaining treatment have to be discussed with the nurses involved. Ten per cent believed that nurses should be able to decide themselves in cases of unbearable suffering to intensify the alleviation of pain and/or other symptoms, even with a possible life-shortening effect. Half of 
Albers, G., Francke, A.L., Veer, A.J.E. de, Bilsen, J., Onwuteaka-Philipsen, B.D. Attitudes of nursing staff towards involvement in medical end-of-life decisions: a national survey study. Patient Education and Counseling: 2014, 94(1), 4-9

nursing staff members (50\%) would be prepared in some cases to administer drugs to bring the patient into a coma until death.

\section{[TABLE 2.]}

\subsection{Factors associated with the attitudes of nursing staff}

Table 3 shows the determining factors in the attitudes of nursing staff regarding involvement in ELD. There were no associations found between age $(40<)$ and the attitudes of nursing staff. All other variables tested were associated to nurses' attitudes towards ELD on at least one statement (having experience with ELD) and at most with 5 statements (working in a hospital versus home care). In comparison to male nursing staff, female nursing staff thought more often that they were in a better position than physicians to assess patients' end-of-life wishes $(\mathrm{OR}=3,2)$ and that nurses should be involved in the whole ELD process ( $\mathrm{OR}=2,7)$, though they agreed less often that decisions with a life-shortening effect could be part of the nursing profession $(\mathrm{OR}=0,35)$. Nursing staff with a life stance or religion that they considered important in their own lives agreed relatively frequently with the statement that they would never be prepared to administer drugs to bring a patient into a coma until death $(\mathrm{OR}=1,9)$, and these professionals agreed less frequently with the statement that decisions with a life-shortening effect may be part of the nursing profession $(\mathrm{OR}=0,45)$.

\section{[TABLE 3. ]}

RNs were more likely than CNAs to think that patients talk rather to them than to a physician $(\mathrm{OR}=1,9)$ and that they were in a better position to assess patient's wishes compared $(\mathrm{OR}=1,5)$. In addition, $\mathrm{RNs}$ agreed more often that decisions to withhold or withdraw life-sustaining treatment ought to be discussed with the nursing staff $(\mathrm{OR}=2,7)$. The proportion of RNs who would be prepared to administer drugs to bring a patient into a coma was higher than for CNAs (OR $=1,7)$.

Nursing staff working in hospitals were significantly more likely than home care nursing staff to think that patients rather talk to a nurse about ELD than to a physician (OR $=2,0)$. In addition, nursing staff in hospitals thought less often than home care staff that they find themselves in a subordinate position $(\mathrm{OR}=0,52)$. In comparison with home care staff, those working in hospitals agreed more often that nurses should be involved in the whole process of end-of-life decision-making $(\mathrm{OR}=4,2)$, and that decisions on withholding or withdrawing life-sustaining treatment should be discussed with the involved nursing staff $(\mathrm{OR}=6,8)$. In addition, hospital nursing staff thought relatively often that nurses could decide for themselves to intensify the alleviation of pain and/or symptoms, even if this could have a lifeshortening side effect $(\mathrm{OR}=2,4)$.

Nursing staff working in a team or department specialized in palliative care were less likely to think that they would find themselves in a subordinate position that makes it difficult to communicate their opinions on $\operatorname{ELD}(\mathrm{OR}=0,50)$. Additionally, they believed more often that physicians are usually prepared to listen to nurses' opinions $(\mathrm{OR}=2,2)$. 
Albers, G., Francke, A.L., Veer, A.J.E. de, Bilsen, J., Onwuteaka-Philipsen, B.D. Attitudes of nursing staff towards involvement in medical end-of-life decisions: a national survey study. Patient Education and Counseling: 2014, 94(1), 4-9

Respondents who had basic education or continuing education about ELD $(\mathrm{OR}=1,9)$, and those who had been involved in medical end-of-life decisions $(\mathrm{OR}=1,6)$ in the last two years agreed more often that patients would rather talk to nurses than to physicians about ELD. Those who had education or continuing education about ELD were also more likely to think that physicians are usually willing to listen to them $(\mathrm{OR}=1,9)$.

\section{DISCUSSION AND CONCLUSION}

\subsection{Discussion}

The opinion of the majority of nursing staff is that they should be involved in the process of end-of-life decision-making. In addition, most nurses think that patients would rather talk to them about ELD than to physicians. This is possibly a consequence of the frequent and close contacts that nurses have with patients. Accordingly, nurses also believe that physicians are prepared to listen to their opinions, which is an important point given that nurses can be an important source of information about patients' wishes. In comparison with home care staff, hospital nursing staff agreed significantly more that they should be involved in the whole process of end-of-life decision-making. In addition, RNs also agreed more often than CNAs with the statement that they ought to be involved in this process.

The way in which ELDs are made might explain why hospital nursing staff indicate that they want to be involved in ELD more often than home care staff do. Nursing staff in hospitals work relatively closely with medical specialists and may have more interdisciplinary team meetings to discuss ELD, whereas home care nurses often work separately from general practitioners. The more frequent contacts between physicians and nursing staff working in a hospital might also explain why respondents working in hospitals were less likely to find themselves in a subordinate position that hinders communication with the physician than home care staff were. However, allowance should be made for the fact that the large majority of hospital nursing staff are RNs whereas half of all home care staff are CNAs. The finding that hospital nursing staff more often than home care nurses agreed with the statement "nurses could decide for themselves to intensify the alleviation of pain and/or symptoms, even if this could have a life shortening side effect" might be explained by the difference in educational level of nursing staff working in a hospital and those working in a home care setting. RNs working in a hospital setting may possibly be more competent and self-confident than home care nursing staff (often CNAs) to choose whether or not to give or intensify medication. Moreover, we also found that RNs agreed more often than CNAs that patients would rather talk to them than to a physician. Furthermore, respondents who had received (continuing or basic) education about ELD agreed more often that patients would rather talk to them than to a physician. In addition, nursing staff working at a specialized palliative care unit or in a team specialized in palliative care were less likely to think that nurses find themselves in a hierarchically subordinate position, and were more likely to think that physicians are prepared to listen to nurses. Remarkably, age and level of 
Albers, G., Francke, A.L., Veer, A.J.E. de, Bilsen, J., Onwuteaka-Philipsen, B.D. Attitudes of nursing staff towards involvement in medical end-of-life decisions: a national survey study. Patient Education and Counseling: 2014, 94(1), 4-9

education were not related to how nursing staff perceived physicians' willingness to listen to nurses' opinions about terminally ill patients.

A previous study in Flanders also found that nurses are in general positive about their own potential involvement in ELD [7]. The Netherlands and Flanders have both high standards of palliative care and a liberal policy regarding medical ELD. However, there are some cultural differences: compared to the Flemish, the Dutch known for their more blunt communication style and the flatter hierarchical setups. The Netherlands also has a strong tradition of direct and open communication and a culture within which anything can be discussed, even death and dying [11]. This might explain why, in comparison to Dutch nurses, Flemish nurses found themselves in hierarchically subordinate positions more often (35\% vs. 23\%) and disagreed more often with the statement that physicians are willing to listen to nurses' opinions (21\% vs. $8 \%)$.

An important strength of this study is that respondents were recruited from the large and nationally representative Nursing Staff Panel. We were therefore able to provide insights into how nurses working in hospitals, home care and residential elderly care settings in the Netherlands consider their role and involvement in ELD. Another strength is the relatively high response rate; this might be due to the fact that all participants in the Nursing Staff Panel are in principle willing to complete survey questionnaires regularly. However, using the existing Nursing Staff Panel has also a disadvantage in the sense that nursing staff who are highly committed and dedicated to the nursing profession will probably be over-represented in our study sample. Additionally, there is a limitation in that most questions and statements in the current study were about attitudes to involvement in ELD in general. Future research should therefore focus more on nurses' attitudes to specific types of ELD and on nurses' actual involvement in ELD.

\section{CONCLUSION}

The majority of nursing staff working in hospitals, home care or residential elderly care would like to be involved in ELD. Work setting and level of nursing education were found to be strong determinants of nurses' attitudes to their involvement in ELD. Through the frequent and intense contact nursing staff have with patients and their close relatives nursing staff can function as an important source of information and can provide physicians with relevant information regarding patient's situation and wishes at the end of life. However, hierarchically subordinate positions make it difficult for nursing staff to communicate their opinions on proposed end-of-life decisions to the physician involved. It is interesting to note that nursing staff in specialized palliative care settings or teams were less likely to think that nurses find themselves in a hierarchically subordinate position and were more likely to think that physicians are prepared to listen to nurses. The multidisciplinary nature of specialized palliative care, implying close collaboration and communication between doctors and nursing staff, may explain this finding and may also act as an example for general care settings and care providers. 
Albers, G., Francke, A.L., Veer, A.J.E. de, Bilsen, J., Onwuteaka-Philipsen, B.D. Attitudes of nursing staff towards involvement in medical end-of-life decisions: a national survey study.

Patient Education and Counseling: 2014, 94(1), 4-9

\subsection{Practice implications}

We recommend that the awareness on the important role nurses have and would like to have in ELD with a potential or definite life-shortening effect should be raised, and taken into account in trainings on end-of-life care for nurses and physicians. We also recommend the involvement of nursing staff in the development of multidisciplinary guidelines or standards on ELD in order to improve communication about ELD between patients, nursing staff and physicians.

\section{FUNDING}

The study was funded by the Dutch Ministry of Health.

\section{CONFLICTS OF INTEREST}

The authors have declared no conflicts of interest.

\section{REFERENCES}

[1] Hall S, Petkova P, Tsouros AD, Costantini M, Higginson IJ. Palliative care for older people: better practices; 2011 in press.

[2] Deliens L, Mortier F, Bilsen J, Cosyns M, Vander Stichele R, Vanoverloop J, Ingels K. End-of-life decisions in medical practice in Flanders, Belgium: a nationwide survey. Lancet 2000 November 25;356:1806-11.

[3] H. Kuhse, P. Singer, P. Baume, M. Clark, M. Rickard End-of-life decisions in Australian medical practice Med J Aust, 166 (1997), pp. 191-196

[4] A. van der Heide, L. Deliens, K. Faisst, T. Nilstun, M. Norup, E. Paci, G. van der Wal, P.J. van der Maas End-of-life decision-making in six European countries: descriptive study

Lancet, 362 (2003), pp. 345-350

[5] A.J. de Veer, A.L. Francke, E.P. Poortvliet Nurses' involvement in end-of-life decisions

Cancer Nurs, 31 (2008), pp. 222-228

[6] van Bruchem-van de Scheur GA, van der Arend AJ, bu-Saad HH, van Wijmen FC, Spreeuwenberg $\mathrm{C}$, ter Meulen RH. Alleviation of pain and symptoms with a life-shortening intention. Nurs Ethics 2008;15:682-95.

[7] E. Inghelbrecht, J. Bilsen, F. Mortier, L. Deliens Nurses' attitudes towards end-of-life decisions in medical practice: a nationwide study in Flanders, Belgium Palliat Med, 23 (2009), pp. 649-658

[8] A.J. de Veer, A.L. Francke, R. Buijse, R.D. Friele The use of physical restraints in home care in the Netherlands J Am Geriatr Soc, 57 (2009), pp. 1881-1886

[9] A.J. de Veer, A.L. Francke Attitudes of nursing staff towards electronic patient records: a questionnaire survey Int J Nurs Stud, 47 (2010), pp. 846-854

[10] A.J. de Veer, M.A. Fleuren, N. Bekkema, A.L. Francke Successful implementation of new technologies in nursing care: a questionnaire survey of nurse-users BMC Med Inform Decis Mak, 11 (2011), p. 67

[11] J. Kennedy A well-considered death Uitgeverij Bert Bakker, Amsterdam (2002) 
Albers, G., Francke, A.L., Veer, A.J.E. de, Bilsen, J., Onwuteaka-Philipsen, B.D. Attitudes of nursing staff towards involvement in medical end-of-life decisions: a national survey study.

Patient Education and Counseling: 2014, 94(1), 4-9

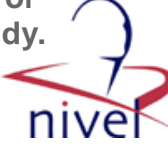

TABLES

Table 1 Characteristics of the Study Population ( $\mathrm{n}=587$ )

\begin{tabular}{|c|c|c|c|c|c|}
\hline & $\begin{array}{c}\text { Total } \\
\\
\mathrm{n}=\mathbf{5 8 7} \\
\%\end{array}$ & $\begin{array}{c}\text { Hospital } \\
\text { n=158 } \\
\%\end{array}$ & $\begin{array}{c}\text { Home } \\
\text { Care } \\
\mathrm{n}=211 \\
\%\end{array}$ & $\begin{array}{c}\text { Home for } \\
\text { the Elderly } \\
\text { n=118 } \\
\%\end{array}$ & $\begin{array}{c}\text { Nursing } \\
\text { Home } \\
\mathrm{n}=106 \\
\%\end{array}$ \\
\hline \multicolumn{6}{|l|}{ Sociodemographic Characteristics } \\
\hline Gender, female & 94 & 87 & 99 & 97 & 93 \\
\hline \multicolumn{6}{|l|}{ Age } \\
\hline$<40$ & 22 & 34 & 16 & 17 & 21 \\
\hline $41>$ & 78 & 66 & 84 & 83 & 79 \\
\hline \multicolumn{6}{|l|}{ Educational level } \\
\hline CNA (3 years) & 53 & 1 & 54 & 90 & 88 \\
\hline $\mathrm{RN}$ (intermediate level) & 31 & 66 & 27 & 8 & 10 \\
\hline RN (bachelor level) & 16 & 33 & 19 & 2 & 2 \\
\hline $\begin{array}{l}\text { Having a belief/religion considered } \\
\text { important in life }\end{array}$ & 28 & 31 & 24 & 37 & 22 \\
\hline \multicolumn{6}{|c|}{ Work-related Characteristics and Experience } \\
\hline \multicolumn{6}{|l|}{ Years of nursing experience } \\
\hline$<5$ years & 6 & 10 & 4 & 3 & 5 \\
\hline $6-20$ years & 39 & 37 & 40 & 37 & 43 \\
\hline $21>$ years & 55 & 53 & 56 & 60 & 52 \\
\hline \multicolumn{6}{|l|}{ Work status, hours per week } \\
\hline$<16$ & 17 & 5 & 25 & 20 & 17 \\
\hline $17-31$ & 58 & 55 & 62 & 56 & 56 \\
\hline $32>$ & 25 & 40 & 14 & 24 & 27 \\
\hline \multicolumn{6}{|l|}{ Working in a team or at a department } \\
\hline \multicolumn{6}{|l|}{ Cared for terminally ill patients during } \\
\hline the last 2 years & 84 & 67 & 88 & 95 & 91 \\
\hline \multicolumn{6}{|l|}{$\begin{array}{l}\text { Number of terminally ill patients cared } \\
\text { for during the last } 2 \text { years }\end{array}$} \\
\hline$<5$ & 39 & 48 & 38 & 39 & 30 \\
\hline $6-15$ & 42 & 27 & 45 & 47 & 46 \\
\hline $16>$ & 19 & 25 & 17 & 14 & 24 \\
\hline $\begin{array}{l}\text { Involved in end-of-life decisions during } \\
\text { the last } 2 \text { years }\end{array}$ & 83 & 82 & 80 & 89 & 86 \\
\hline $\begin{array}{l}\text { Received education or continuous } \\
\text { education on end-of-life decisions }\end{array}$ & 55 & 57 & 57 & 43 & 58 \\
\hline
\end{tabular}


Albers, G., Francke, A.L., Veer, A.J.E. de, Bilsen, J., Onwuteaka-Philipsen, B.D. Attitudes of nursing staff towards involvement in medical end-of-life decisions: a national survey study.

Patient Education and Counseling: 2014, 94(1), 4-9

Table 2 Attitudes of Nurses to End-of-Life Decisions and their Role in End-of-Life Decisions

\begin{tabular}{|c|c|c|c|c|}
\hline & & $\begin{array}{c}\text { Disagree } \\
\%\end{array}$ & $\begin{array}{c}\text { Neutral } \\
\%\end{array}$ & $\begin{array}{c}\text { Agree } \\
\%\end{array}$ \\
\hline \multicolumn{5}{|c|}{ Statements on the murse-patient relationship in end-of-life decisions } \\
\hline 1 & Patients would rather talk to a nurse about ELDs than to a physician. & 9 & 27 & 64 \\
\hline 2 & $\begin{array}{l}\text { Nurses are in a better position to assess patients' end-of-life wishes than } \\
\text { physicians are. }\end{array}$ & 22 & 40 & 38 \\
\hline \multicolumn{5}{|c|}{ Statements on the murse-physician relationship in end-of-life decisions } \\
\hline 3 & $\begin{array}{l}\text { Nurses find themselves in a hierarchically subordinate position that makes it } \\
\text { difficult to communicate their opinions on proposed ELDs to the physician } \\
\text { involved. }\end{array}$ & 45 & 32 & 23 \\
\hline 4 & $\begin{array}{l}\text { Physicians are usually prepared to listen to the nurses' opinions about } \\
\text { terminally ill patients. }\end{array}$ & 8 & 20 & 72 \\
\hline \multicolumn{5}{|c|}{ Statements on nurses' roles and tasks in end-of-life decisions } \\
\hline 5 & $\begin{array}{l}\text { The core professional value of nursing is the patient's well-being, which may } \\
\text { also include decisions with a life-shortening effect. }\end{array}$ & 14 & 15 & 71 \\
\hline 6 & $\begin{array}{l}\text { Because of their central role in the care of the patient, nurses should be } \\
\text { involved in the whole process of end-of-life decisions. }\end{array}$ & 7 & 19 & 74 \\
\hline 7 & $\begin{array}{l}\text { Whenever a decision is made to withhold or withdraw life-sustaining } \\
\text { treatment from a patient, this should be discussed with the nurses involved. }\end{array}$ & 20 & 22 & 58 \\
\hline 8 & $\begin{array}{l}\text { Whenever a terminally ill patient is suffering unbearably, nurses can decide } \\
\text { themselves to intensify the alleviation of pain and/or symptoms, which may }\end{array}$ & 76 & 14 & 10 \\
\hline & have a life-shortening side effect. & & & \\
\hline 9 & $\begin{array}{l}\text { I would under no circumstances be prepared to administer drugs to bring the } \\
\text { patient into a coma until death. }\end{array}$ & 50 & 23 & 27 \\
\hline
\end{tabular}

Missing data range from 28 to 34 . 
Albers, G., Francke, A.L., Veer, A.J.E. de, Bilsen, J., Onwuteaka-Philipsen, B.D. Attitudes of nursing staff towards involvement in medical end-of-life decisions: a national survey study.

Patient Education and Counseling: 2014, 94(1), 4-9

Table 3 Relationship between Background and Work-related Characteristics versus Agreement with Statements on Medical End-of-Life Care Decisions ${ }^{\mathrm{a}}$

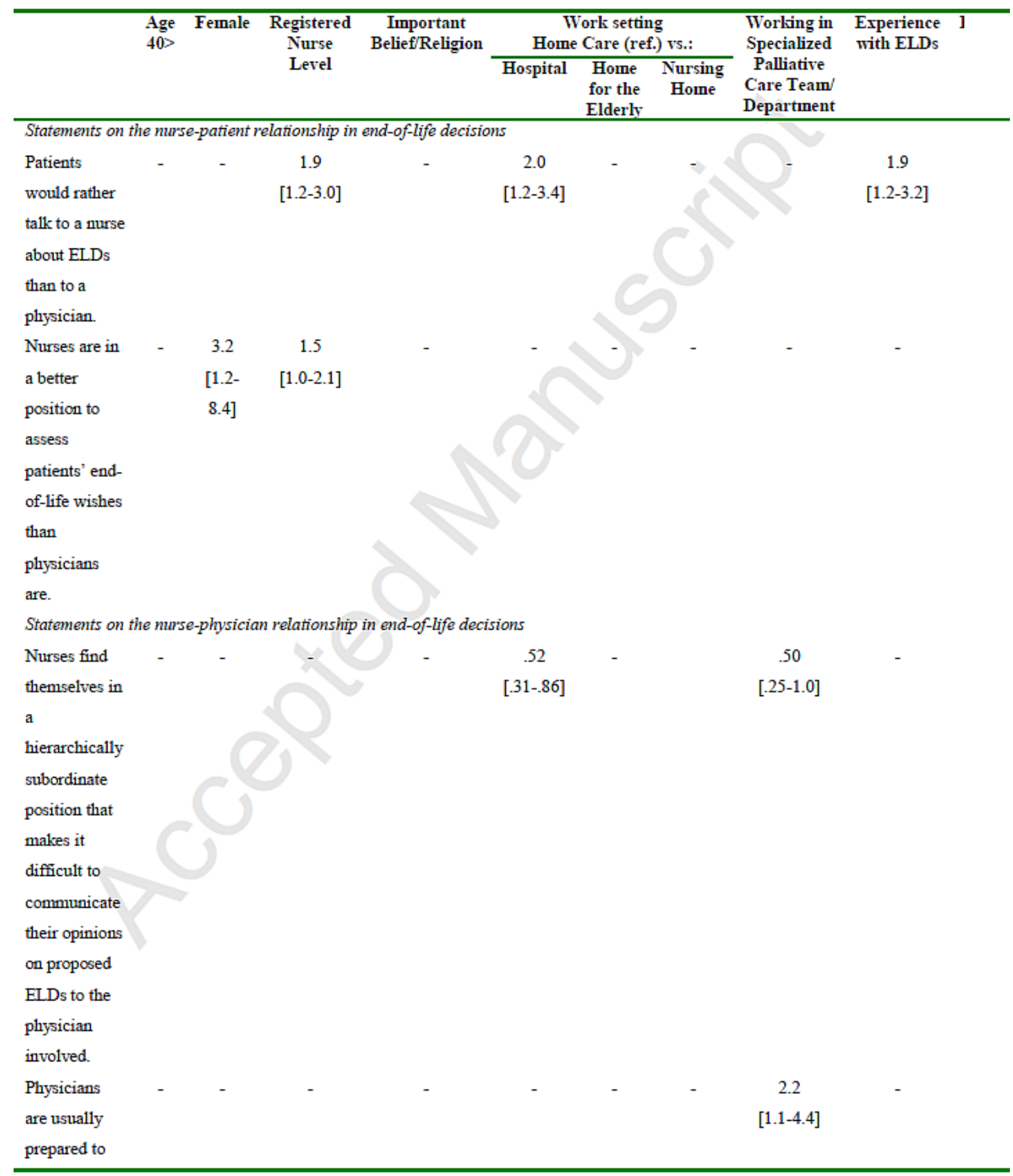

